\title{
"Adulterated" Androstenedione: What FDA's Action against Andro Means for Industry
}

\author{
Richard D. Collins ${ }^{1}$ and Alan H. Feldstein ${ }^{2}$ \\ Collins, McDonald \& Gann, P.C., Carle Place, NY ${ }^{1}$, Studio City, CA ${ }^{2}$. Sports Nutrition Review \\ Journal.1(1):52-60,2004. Address correspondence to RCollins@.cmgesq.com.
}

Received April 23, 2004/Accepted May 18, 2004/Published (online)

\begin{abstract}
On March 11, 2004, the Food and Drug Administration (FDA) pronounced that dietary supplement products containing androstenedione were adulterated new dietary ingredients under the Dietary Supplement Health and Education Act of 1994 (DSHEA). The FDA issued a press release, held a news conference, and sent warning letters to 23 companies that had manufactured, marketed or distributed the products containing androstenedione. In its warning letters, FDA threatened possible enforcement actions for noncompliance. The authors have looked at the warning letters, statutes, regulations, and media reports to analyze the legal grounds and standards upon which FDA acted against androstenedione and question the appropriateness of the action taken. They have also looked at the negative impact that FDA's lack of communication and cooperation with Industry is having upon the fitness nutrition industry and the marketing of dietary supplements containing new dietary ingredients. The authors also suggest what might be done to ameliorate this escalating problem including more cooperation between FDA and Industry and more research into the benefits and use of supplement products. Sports Nutrition Review Journal. 1(1):52-60, 2004.
\end{abstract}

Key Words: androstenedione, sport nutrition, dietary supplements, DSHEA

\section{INTRODUCTION}

On March 11, 2004, the Food and Drug Administration (FDA) pronounced that dietary supplement products containing androstenedione were adulterated new dietary ingredients under the Dietary Supplement Health and Education Act of 1994 (DSHEA). Despite the lack of evidence of an imminent health hazard and instead of the formal administrative procedure of issuing a proposed rule and inviting public comment, FDA took unilateral action, issued a press release, held a news conference, and sent warning letters to 23 companies that had manufactured, marketed or distributed the products containing androstenedione. In its warning letters, FDA threatened possible enforcement actions for noncompliance. The effect was to cause retailers, manufacturers and distributors alike to cease selling products containing androstenedione without FDA having had meaningful dialogue with Industry before taking action. This action, along with others of FDA in the past, is sadly illustrative of the lack of cooperation and communication that exists between FDA and Industry. FDA's antagonistic attitude towards dietary supplements in general and the fitness nutrition industry in particular could result in an increasing encroachment upon DSHEA.

This attitude, combined with sensationalized media reports, anti-supplement leanings by some members of Congress, and a general institutionalized bias against alternative health approaches, has created an environment in which the freedoms of Americans to make their own health choices under DSHEA are now in grave jeopardy. 
This article will analyze the legal grounds and standards upon which FDA acted against androstenedione. It will look at the negative impact that FDA's lack of communication and cooperation with Industry is having upon the fitness nutrition industry and the marketing of dietary supplements containing new dietary ingredients. Finally, it will suggest what might be done to ameliorate these escalating problems.

\section{PUBLIC HEALTH PROTECTIONS ON DIETARY SUPPLEMENTS PROVIDED UNDER DSHEA}

In 1994, DSHEA ${ }^{3}$ was passed with the unanimous consent of Congress. As discussed in a recent law review article, FDA's anti-supplement tactics provoked a groundswell of legislative criticism ultimately leading to DSHEA: ${ }^{4}$

DSHEA was enacted because FDA was viewed as distorting the law that existed before DSHEA to try improperly to deprive the public of safe and popular dietary supplement products. ... In its official report about the need for DSHEA to curtail excessive regulation of dietary supplements by FDA, the Senate Committee on Labor and Human Resources ... stated explicitly "in fact, FDA has been distorting the law in its actions to try to prevent the marketing of safe dietary supplement substances." 5 The Senate Committee also concluded, "FDA has attempted to twist the statute [i.e., the provisions of the FDCA, as it then existed] in what the Committee sees as a result-oriented effort to impede the manufacture and sale of dietary supplements.",6

DSHEA represented a sharp rebuke to FDA's unreasonable regulatory tactics. It was FDA's own actions that brought about the need for DSHEA. However, DSHEA did not leave FDA paralyzed. Despite media statements to the contrary, the industry is not an unregulated industry. In fact, DSHEA ensured FDA's authority to provide legitimate protections for the public health. The Food,
Drug, and Cosmetic Act (FDCA) ${ }^{7}$ prohibits introducing adulterated products into interstate commerce. ${ }^{8}$ The penalties for a first conviction can include a fine of up to $\$ 1,000$, imprisonment for up to one year, or both. ${ }^{9}$ Subsequent convictions, or convictions for offenses committed with the intent to defraud or mislead, can include fines of up to $\$ 10,000$, imprisonment of up to three years, or both. ${ }^{10}$

Several grounds exist by which unsafe dietary supplements can be deemed "adulterated". ${ }^{11}$

While the Secretary of Health and Human Services has the power to declare a dangerous supplement to be an "imminent hazard" to public health or safety and suspend sales of the product, ${ }^{12}$ FDA also has the authority to protect consumers from dietary supplements that don't present an imminent hazard to the public but do present certain risks of illness or injury to consumers. Two provisions are relevant to our examination.

The first provision, which applies to all dietary supplements, states that a supplement shall be deemed adulterated if it presents "a significant or unreasonable risk of illness or injury under ... conditions of use recommended or suggested in labeling, or ... if no conditions of use are suggested or recommended in the labeling, under ordinary conditions of use." 13 The standard doesn't require proof that consumers have actually been harmed, or even that a product will harm anyone. It was under this provision that FDA, after seven years, numerous criticisms including a negative report from the General Accounting Office ${ }^{14}$ and a storm of public debate, concluded that dietary supplements containing ephedra presented an unreasonable risk. However, the conclusion FDA drew and its reasoning to declare products containing ephedra adulterated utilized a new and novel approach that distorts the definition of significant or unreasonable risk. In the case of ephedra, FDA did an analysis of whether the product's known or reasonably likely risks outweigh its known or reasonably likely benefits. Thus, this is no longer a straight safety analysis, but is now a risk/benefit 
analysis, which is not what is called for in the statute. Even though ephedra had been shown beneficial for short-term weight loss, FDA used this standard to conclude that these benefits did not outweigh the risks that FDA felt ephedra products posed. ${ }^{15}$ Pending litigation challenging FDA's actions will determine whether or not FDA's analysis is correct. ${ }^{16}$ If this standard withstands legal challenge, then this definition will apply to all other supplements and many popular and less controversial supplements will also be at risk of being removed from the market.

\section{DSHEA PROTECTIONS AGAINST ADULTERATED "NEW DIETARY INGREDIENTS"}

The second provision addresses only dietary supplements containing new dietary ingredients, for which FDA believes there may be inadequate information to provide a reasonable assurance that the ingredient does not present a significant risk of illness or injury. Recognizing that new and untested dietary supplement products may pose unknown health issues, DSHEA distinguishes between products containing dietary ingredients that were already on the market and products containing new dietary ingredients that were not marketed prior to the enactment of the law. ${ }^{17} \mathrm{~A}$ "new dietary ingredient" is defined as a dietary ingredient that was not marketed in the United States before October 15, $1994 .^{18}$

DSHEA grants FDA greater control over supplements containing new dietary ingredients. A new dietary ingredient is deemed adulterated and subject to FDA enforcement sanctions unless it meets one of two exemption criteria: either (1) the supplement in question contains "only dietary ingredients which have been present in the food supply as an article used for food in a form in which the food has not been chemically altered"; or (2) there is a "history of use or other evidence of safety" provided by the manufacturer or distributor to FDA at least 75 days before introducing the product into interstate commerce. ${ }^{19}$ The first criterion is silent as to how and by whom presence in the food supply as food articles without chemical alteration is to be established. The second criterion - applicable only to new dietary ingredients that have not been present in the food supply - requires manufacturers and distributors of the product to take certain actions. Those actions include submitting, at least 75 days before the product is introduced into interstate commerce, information that is the basis on which a product containing the new dietary ingredient will "reasonably be expected to be safe." 20 That information would include: (a) the name of the new dietary ingredient and, if it is an herb or botanical, the Latin binomial name; (b) a description of the dietary supplement that contains the new dietary ingredient, including the (i) level of the new dietary ingredient in the product; (ii) conditions of use of the product stated in the labeling or if no conditions of use are stated, the ordinary conditions of use; and (iii) history of use or other evidence of safety establishing that the dietary ingredient, when used under the conditions recommended or suggested in the labeling of the dietary supplement, will be reasonably expected to be safe.

There is no guidance as to what evidence is required to establish a reasonable expectation of safety. ${ }^{21}$ In fact, FDA specifically states that the person submitting the application is responsible for determining what information provides the basis for the conclusion that the product will be reasonably expected to be safe. By not providing guidance one could argue that FDA is giving itself a wide berth to arbitrarily decide what ingredients to approve or disapprove. The only hint given is that FDA expects the applicant to "consider the evidence of safety found in the scientific literature, including an examination of adverse effects associated with the use of the substance." 22 Thus, it appears that the question should be one of safety alone as opposed to a safety and efficacy analysis, which in turn naturally progresses to a risk/benefit analysis. This is a much different 
and more difficult, if not impossible, standard for a NDI to meet.

\section{FDA'S ACTION AGAINST ANDROSTENEDIONE}

Supplements containing androstenedione were introduced in the mid 1990's and were promoted as a natural way to help increase strength and muscle mass and to combat the effects of the aging process in older men, much of which is attributed to declining testosterone levels. Like DHEA, androstenedione is a naturally derived precursor to testosterone. Androstenedione converts directly to testosterone in the metabolic pathway. The fact that it is naturally derived and, as described below present in the food supply, is important in relation to the action taken by FDA.

In its press release $\mathrm{e}^{23}$ and warning letters ${ }^{24}$, FDA declared androstenedione to be an adulterated new dietary ingredient based on its position that no evidence demonstrates "that androstenedione was lawfully marketed as a dietary ingredient in the United States before October 15, 1994." 25 It would seem to be correct that androstenedione was not marketed before 1994, given that the first commercial marketing of products containing androstenedione appears to have been in 1996. Further, a review of FDA's electronic database indicates no submission of an application for a new dietary ingredient involving androstenedione. ${ }^{26}$ Interestingly, however, FDA goes beyond the words of the statute and uses the term "lawfully marketed" in their letters instead of simply "marketed." The implication is that to receive "grandfathered" status into DSHEA as a pre1994 supplement ingredient, the product must not only have been marketed but must have met the additional requirement of having been lawfully marketed. At least one commentator has interpreted this language to impose a burden on Industry to prove the product was generally regarded as safe pre-1994 - an impossible standard for any product that was not explicitly affirmed as such by FDA prior to the enactment of DSHEA. ${ }^{27}$

Assuming that androstenedione is indeed a new dietary ingredient, FDA could determine that products containing androstenedione are adulterated under DSHEA unless they meet either of the two exemption criteria stated above.

Accordingly, it appears that the question of exemption turns on (a) whether or not androstenedione is present in the food supply as an article used for food without chemical alteration, and (b) if not, could the product satisfy the requirement of reasonable expectation of safety.

With respect to the first exemption, according to scientific journals, androstenedione is indeed present in the food supply without chemical alteration. ${ }^{28}$ Had there been open communication between FDA and Industry, the scientific evidence that androstenedione is present in the foods we eat could have been presented and discussed with FDA. Moreover, until 1998, which is the date for the most recent information, there were no reports of adverse events reported on FDA's database. ${ }^{29}$ Adverse events are one of the few specific pieces of information that FDA sets forth in their "information" about what safety data they require. ${ }^{30}$

FDA's policy creates a nearly impossible procedure to demonstrate safety. FDA's requirements to show safety have never been articulated. On FDA's web site the following statement appears:

You are not limited in what evidence you may rely on in determining whether the use of a new dietary ingredient will reasonably be expected to be safe. (See section 413(a)(2) of the act (21 U.S.C. $350 b(a)(2))$. You must provide a history of use or other evidence of safety establishing that the dietary ingredient, when used under the 
conditions recommended or suggested in the labeling of the dietary supplement, will reasonably be expected to be safe. To date, we have not published guidance defining the specific information that the submission must contain. Thus, you are responsible for determining what information provides the basis for your conclusion. Nonetheless, we expect that -- in making a determination that a new dietary ingredient is reasonably expected to be safe, -you will consider the evidence of safety found in the scientific literature, including an examination of adverse effects associated with the use of the substance (emphasis added). ${ }^{31}$

First, no mention is made of efficacy; the necessary component for a risk/benefit analysis. Second, a lack of guidance by FDA has created a circular process where at any time the agency can declare that the product does not satisfy its unspoken standards and deem the product adulterated.

Both FDA and Industry must take responsibility for this acrimonious and hostile environment. FDA must rid itself of its institutionalized bias against supplements and have meaningful and cooperative discussions with Industry. Industry must take it upon itself to conduct further safety research of its products. If this had been done, the fate of androstenedione might have been decidedly different. It is too late to have fruitful cooperation between the agency and Industry once there are press conferences, press releases, warning letters, and products pulled from store shelves.

How would FDA have responded if Industry had submitted the scientific literature on androstenedione to FDA? What FDA would have done is implied in its warning letters. After citing androstenedione as an adulterated new dietary ingredient, FDA directly addresses the safety issue:

Even if the required notification had been submitted, based on what we know now, we know of no evidence that would establish that your product is not adulterated. In the absence of a history of use or other evidence of safety establishing that androstenedione, when used under the conditions recommended or suggested in the labeling of your product, will reasonably be expected to be safe, a product containing andro is adulterated under 21 U.S.C. 342(f)(1)(B) and 350b(a) as a dietary supplement that contains a new dietary ingredient for which there is inadequate information to provide reasonable assurance that such ingredient does not present a significant or unreasonable risk of illness or injury. ${ }^{32}$

Thus, FDA suggests that even if industry had provided proper notification pursuant to statute, its position is that there exists inadequate information from which to conclude that androstenedione could be reasonably expected to be safe as a dietary ingredient. In fact, FDA believes to the contrary according to its androstenedione "Questions and Answers" web page:

Based on a limited number of studies of andro's actions in humans and existing knowledge about steroid hormone metabolism and action in the body, FDA believes that the use of dietary supplements containing andro may increase the risk of serious health problems because of their conversion in the body to active hormones with androgenic and estrogenic properties. ${ }^{33}$

A review of the "limited number" of andro studies and a scientific analysis of their meaning is beyond the scope of this article. ${ }^{34}$ However, if Industry desires to continue to develop and market innovative new dietary products it is going to have to adopt a more aggressive role in conducting research and 
publishing studies. It is going to have to forge stronger and more extensive relationships with the scientific community to analyze its products and their effects. It is then going to have to ensure that those studies are brought to the attention of the FDA and others.

\section{RAMIFICATIONS FOR THE DIETARY SUPPLEMENT INDUSTRY}

The next question that must be asked is what does this mean for other dietary supplements? The loss of ephedra and androstenedione are strong signals of FDA's intent to reach as far as possible in their attempt to regulate supplements. Anyone attuned to what is transpiring in this Industry is aware that there is a movement to undo most of the framework of DSHEA. The fallout may have ramifications far beyond the fitness nutrition community, impacting the mainstream vitamin industry and traditional herbalists.

Senator Richard Durbin of Illinois, a longtime critic and opponent of the dietary supplement industry, recently addressed Congress in promoting a bill he is sponsoring that would put safety burdens on Industry and criminalize certain supplements:

People unsuspectingly go into these health food stores, vitamin stores, and see the dietary supplements with all sorts of claims on them; they buy them, they use them, and the consumers of America become the guinea pigs.

...

[I] they are dangerous, if they hurt someone, clearly then the Government will take them off the shelf, right? No, I am sorry, that is not right because understand that the law we passed at the request of the industry does not require dietary supplement manufacturers to report to the Government when people are literally dying from the products they sell.
I am happy to see the Institute of Medicine creating momentum for Congress to finally make a decision. I am happy to see the administration, after more than a year of urging, finally banning ephedra, but more has to be done. Today as we speak, innocent children and consumers across America are buying products which they presume to be safe and they are not. ${ }^{35}$

The Senator's statement about the Institute of Medicine of the National Academies refers to a recent publication suggesting a new framework for evaluating the safety of dietary supplement ingredients, ${ }^{36}$ using a "spectrum of concern" model more appropriate to the review of prescription drugs. While the effort is a noble one, Industry should be careful that such an approach is not the first step backwards towards a pre-DSHEA environment and a movement to define many dietary supplement ingredients as drugs.

No one can or should object that manufacturers and distributors of products should be able to substantiate the claims they make about their products. No one can argue that safety research on products should be conducted. Any company that manufactures or distributes dietary supplements should have a comprehensive policy for handling reports of serious adverse health events. Finally, any manufacturer or distributor should have proper labels on their products with appropriate cautions and warnings.

There also needs to be more rational reporting within the media. An extreme example of the media bias against sports supplements involved the reported story of a 22-year-old "would-be bodybuilder" who claimed that his use of creatine monohydrate at recommended doses for three and a half months caused liver and kidney failure and the loss of the full use of his legs. ${ }^{37}$ The story begins by 
describing the "deep blue and red scar [that] carves the skin on the outside of both of [his] legs, from his hips to his ankles. Orthopedic surgeons' scalpels have sliced them open again and again over the past five months to save his life and legs." It continues with: "“After the fourth day they wanted to amputate both legs at the hip,' he said. 'They were afraid the decay would spread to my lower intestines." Finally, the story proceeds to: "What caused all the problems? 'The doctors ... told me it was the creatine,' he said. 'My body wouldn't process it.' It ended up poisoning him." The story was tossed to the public without any comments from nutrition experts or even the doctors who supposedly attributed the horrific symptoms to creatine. This disconnect between the fitness community's experience with these products and the questionable scare stories reported by the media does nothing but perpetuate an atmosphere of confusion and mistrust.

More importantly, FDA must also assume some responsibility for this state of affairs. If Industry is going to be compelled to institute policies and procedures then there must also be changes within FDA. This means a change in attitude towards supplements, hiring people within the FDA Center for Food Safety and Applied Nutrition (CFSAN) responsible for supplements who understand and support the use of supplements and the appointment of an ombudsman within CFSAN as there are in other centers within FDA.

This lack of guidance and communication with FDA makes it very difficult for anyone to know whether or not they could even comply with FDA's requirements. As was evidenced by the process in Ephedra, FDA did not, in any meaningful way, communicate with Industry to learn about Industry's experiences. Even after Industry compiled a marketing study ${ }^{38}$, FDA did not communicate with Industry about the findings. ${ }^{39}$ The lack of communication between FDA and Industry fosters an atmosphere of frustration and suspicion that benefits neither FDA nor Industry, and most importantly is a detriment to the American public. Until there is better cooperation and communication between FDA and Industry and until there are people within FDA who support the use of dietary supplements this will continue to be a problem.

It is hoped that before FDA takes any other actions or makes any other pronouncements about dietary supplement ingredients, a mutually cooperative dialogue can take place. Even if that were to occur, however, there is another issue to consider. While FDA enforcement against other dietary supplement ingredients is possible, future action may be legislative rather than regulatory. Several federal bills are pending which would relegate prohormone products to controlled substance status, making their distribution a federal felony and their mere possession by healthconscious, adult consumers a federal crime. ${ }^{40}$ This illogical step has no basis in fact given that there is no scientific evidence that prohormone products meet the test of a controlled substance. Controlled substances are drugs - such as cocaine, heroin and LSD or other substances with addictive qualities that may lead to physical or psychological dependence. ${ }^{41}$ There is not a scintilla of evidence that these products have been exerting addictive effects or leading to dependency issues. The momentum behind legislative action is due more to the current media frenzy over the use of steroidal "doping" in sports. Regulating these products is taking the more political route of legislation than regulation by FDA after notice and comment. There is the very real possibility that all prohormone products will be legislatively removed from the marketplace without scientific or factual support.

\section{CONCLUSION}

FDA's action on androstenedione suggests a heightened enforcement policy against what 
the agency deems to be adulterated new dietary ingredients. Bringing products to market that do not meet either of the two exemption criteria of 21 U.S.C. 350(b) may not be overlooked in the future. If a new dietary ingredient is exempted from adulterated status because it is present in the food supply as an article used for food in a form in which the food has not been chemically altered, it is prudent to document that information prior to marketing the product or even to communicate that information to FDA. If a new dietary ingredient is not exempted from adulterated status based upon the food supply exemption, then pre-market notification of history of use or other evidence of safety establishing that the dietary ingredient, when used under the conditions recommended or suggested in the labeling of the dietary supplement, will be reasonably expected to be safe must be provided to FDA at least 75 days before the product is introduced into interstate commerce.
The dietary supplement industry as regulated by DSHEA is still a relatively new industry. Like any new industry it is going through growing pains. However, for the industry to survive it must begin to attempt to establish communication with legislative representatives and administrative agencies, like FDA. It must begin an era of cooperation among its members, no matter how competitive they may be in business, to establish procedures and to develop science. Failure to do so will result in constantly being buffeted by the winds of public opinion and sensationalistic journalism. At the same time, our representatives and government officials must take a close look at the inherent and institutionalized bias that exists against dietary supplements within government and begin to find ways to undo that bias so that productive and meaningful dialogue can take place. Until that happens, the American public will be disadvantaged.

\section{FOOTNOTES \& REFERENCES}

1 Mr. Collins practices in the firm of Collins, McDonald \& Gann, P.C., primarily in the areas of nutritional supplement law, performance drugs, and criminal defense. A former certified personal trainer, he is the author of the popular book Legal Muscle, a monthly columnist for Muscular Development magazine, and the legal advisor to the International Federation of BodyBuilders.

2 Mr. Feldstein is of counsel to Collins, McDonald \& Gann. He concentrates in the area of nutritional supplement law, having served as general counsel for a dietary supplement company for seven years. In the 1990s, he was the catalyst for assembling several industry associations in the effort to educate the public, legislators and administration officials on the facts and science regarding dietary supplements containing ephedra.

3 Pub. L. No. 103-417, 108 Stat. 4325 (codified at 21 U.S.C. 301 et seq. (1994)) (signed by the President October 25, 1994).

4 McNamara S. and Siegner W., "FDA Has Substantial and Sufficient Authority to Regulate Dietary Supplements," 57 Food \& Drug L.J. 15, 2002, referencing 140 Congressional Record-House of Representatives 11173-11179 (October 6, 1994);

140 Congressional Record-Senate 14798-14800 (October 7, 1994).

5 Ibid, citing Senate Report No. 103-410, 103d Congress, 2d Session, Committee on Labor and Human Resources (October 8, 1994), at page 16.

${ }^{6}$ Ibid, citing Senate Report No. 103-410, at page 22.

7 Pub. L. No. 75-717, 52 Stat. 1040 (1938) (codified as amended 21 U.S.C. 301 et seq. (1994)).

821 U.S.C. $\$ 331(\mathrm{a})$ and (v).

921 U.S.C. $\$ 333(\mathrm{a})(1)$.

${ }^{10} 21$ U.S.C. $\$ 333(\mathrm{a})(2)$.

1121 U.S.C. $\$ 342(\mathrm{f})(1)$ and $350 \mathrm{~b}(\mathrm{a})$.

${ }^{12}$ Provided that the Secretary then initiates on-the-record rulemaking to affirm or withdraw the declaration. See, 21 U.S.C. $\S$ $342(\mathrm{f})(1)$.

1321 U.S.C. $\S 342(f)(1)(A)$.

${ }^{14}$ GAO Report, "Dietary Supplements: Uncertainties in Analyses Underlying FDA's Proposed Rule on Ephedrine Alkaloids," June 25, 1999, available at www.gao.gov/archive/1999/h299090.pdf.

${ }^{15}$ See, "Final Rule Declaring Dietary Supplements Containing Ephedrine Alkaloids Adulterated Because They Present an Unreasonable Risk," 69 Fed. Reg. 6788 (February 11, 2004), available at http://www.cfsan.fda.gov/ /rd/fr040211.html.

${ }^{16}$ See, NVE, Inc. v. Dept. of Health and Human Services, et al., No. 2:04-cv-00999-JAP-MCA, D. N.J. (2004).

${ }^{17}$ A "dietary ingredient" may be a vitamin, a mineral, an herb or other botanical, an amino acid, a dietary substance for use by man to supplement the diet by increasing the total dietary intake, or a concentrate, metabolite, constituent, extract, or combination of any of these. See, 21 U.S.C. 321 (ff)(1).

${ }^{18} 21$ U.S.C. $\$ 350 \mathrm{~b}(\mathrm{c})$. 
${ }^{19} 21$ U.S.C. $\$ 350 b(a)$.

${ }^{20}$ See, FDA, Center for Food Safety \& Applied Nutrition (CFSAN), "New Dietary Ingredients in Dietary Supplements," available at http://www.cfsan.fda.gov/ dms/ds-ingrd.html\#whatis. See also, 21 CFR § 190.6.

21 "To date, we have not published guidance defining the specific information that the submission must contain. Thus, you are responsible for determining what information provides the basis for your conclusion." FDA, CFSAN, available at

${ }_{22} \frac{\mathrm{http}}{\mathrm{Id}}$. http://www.cfsan.fda.gov/ dms/ds-ingrd.html

${ }^{23}$ FDA, CFSAN, Androstenedione Press Release, available at http://www.fda.gov/bbs/topics/news/2004/hhs 031104.html.

${ }^{24}$ FDA, CFSAN, Androstenedione Warning Letters, available at http://www.cfsan.fda.gov/ dms/andrlist.html\#letter.

${ }^{25} \mathrm{Id}$.

${ }^{26}$ FDA, 9/10/01 UPDATE to FDA's Table of New Dietary Ingredient Notifications, available at http://www.cfsan.fda.gov/ dms/dsingrd.html\#whatis.

${ }^{27}$ Siegner W, "FDA's Actions on Ephedra and Androstenedione: Understanding How They Erode the Protections of DSHEA," Paper for FDLI's $47^{\text {th }}$ Annual Conference, April 16-4, 2004.

${ }^{28}$ Johnson SK, Lewis PE, Inskeep EK, "Steroids and cAMP in follicles of postpartum beef cows treated with norgestomet," J Anim Sci. 1991 Sep;69(9):3747-53. Braden TD, King ME, Odde KG, Niswender GD, "Development of preovulatory follicles expected to form short-lived corpora lutea in beef cows," J Reprod Fertil. 1989 Jan;85(1):97-104. Wise TH, Caton D, Thatcher WW, Lehrer AR, Fields MJ, "Androstenedione, dehydroepiandrosterone and testosterone in ovarian vein plasma and androstenedione in peripheral arterial plasma during the bovine oestrous cycle," J Reprod Fertil. 1982 Nov;66(2):513-8.

${ }^{29}$ Margolis M, "Dietary Supplements: Caveat Athlete," available at http://www.law.uh.edu/healthlawperspectives/Food/980910Dietary.html. Also, concurrent with this article the authors are planning on filing a FOIA request to FDA to determine the number, if any, of adverse event reports associated with androstenedione which have been reported to FDA.

${ }^{30}$ See, supra, note 21 .

${ }^{31} \mathrm{Id}$.

${ }^{32}$ Supra, note 24

${ }^{33}$ Online at http://www.cfsan.fda.gov/ dms/androqa.html

${ }^{34}$ For an primer with extensive references, see Antonio J., Chromiak, J., and Street, J, “Androgens and GH Releasers,” pages 160 to 178, in Sports Supplements, Antonio, J and Stout, JR, Eds. (Lippincott Williams \& Wilkins, 2001).

${ }^{35}$ Comments of Senator Richard Durbin, Congressional Record (Senate, April 1, 2004), pages S3545-48, available at http://thomas.loc.gov/cgi-bin/query/R?r108:FLD001:S53548.

${ }^{36}$ Institute of Medicine (IOM) report "Dietary Supplements: A Framework for Evaluating Safety," available at http://www.iom.edu/report.asp?id=19578.

37 Archbold, M, "Bigger, stronger ... but at a terrible cost: Bodybuilder undergoes battery of surgeries to save life, legs", The King County Journal, April 02, 2004, available at http://www.kingcountyjournal.com/sited/story/html/160240.

38 "Ephedra Survey Results: 1995-1999”, Food \& Drug Administration Docket 1995-N-0304.

${ }^{39}$ One of the authors, Alan Feldstein, was head of the Ephedra Committee of the American Herbal Products Association which was responsible for arranging for the Arthur Anderson Survey. The Committee was never contacted after the survey was released and submitted to FDA.

${ }^{40}$ For examples, S. 722, S. 1780, and S. 2195 in the Senate, and H.R. 207 and H.R. 3866 in the House, all of which target prohormones.

${ }^{41} 21$ U.S.C. $\S 812$. 